\title{
Macrophage activation syndrome in a patient with adult-onset Still's disease following first COVID-19 vaccination with BNT162b2
}

\author{
Frédéric Muench ${ }^{1 *}\left(\mathbb{D}\right.$, Martin Krusche ${ }^{2,3}$, Leif Erik Sander ${ }^{4}$, Thomas Rose ${ }^{2}$, Gerd-Rüdiger Burmester ${ }^{2}$ and
} Udo Schneider ${ }^{2}$

\begin{abstract}
Background: Adult-onset Still's disease (AOSD) is an autoinflammatory multi-systemic syndrome. Macrophage activation syndrome (MAS) is a potentially life-threatening complication of AOSD with a mortality rate of 10-20\%. Especially viral infection is thought to be a common trigger for development of MAS. On the other hand, the occurrence of MAS following vaccinations is extremely rare and has been described in a few cases after measles or influenza vaccinations and more recently after ChAdOx1 nCoV-19 (COVID-19 viral vector vaccine, Oxford-AZ).

Case presentation: We report the case of a twenty-year-old female with adult-onset Still's disease (AOSD), who developed a MAS six days after receiving her first COVID-19 vaccine dose of BNT162b2 (mRNA vaccine, BioNTech/ Pfizer) with ferritin levels of 136,680 $\mu \mathrm{g} / \mathrm{l}$ (ref.: 13-150 $\mu \mathrm{g} / \mathrm{l})$.

Conclusions: To the best of our knowledge, this is the first case report of development of MAS in a patient with preexisting AOSD after vaccination in general, and SARS-CoV-2 vaccination in particular. The new mRNA vaccines have generally shown a reassuring safety profile, but it has been shown that nucleic acids in general, including mRNA can act as pathogen-associated molecular patterns that activate toll-like receptors with extensive production of proinflammatory cytokines and further activation of immune cells. Proving an interferon 1 response in our patient directly after vaccination, we think that in this particular case the vaccination might have acted as trigger for the development of MAS. Even if it remains difficult to establish causality in the case of rare adverse events, especially in patients with autoimmune or autoinflammatory conditions, these complications are important to monitor and register, but do not at all diminish the overwhelming positive benefit-risk ratio of licensed COVID-19 vaccines.
\end{abstract}

Keywords: Adult-onset Still's disease, Macrophage activation syndrome, Vaccine reaction

\section{Background}

Adult-onset Still's disease AOSD is an autoinflammatory multi-systemic syndrome. Macrophage activation syndrome (MAS) is a potentially life-threatening

\footnotetext{
*Correspondence: frederic.muench@charite.de

${ }^{1}$ Department of Nephrology and Medical Intensive Care, Charité -

Universitätsmedizin Berlin, Berlin, Germany

Full list of author information is available at the end of the article
}

complication of AOSD, which occurs in up to $12-14 \%$ of AOSD patients and has a mortality rate of $10-20 \%$ [1]. Therefore, early detection and immediate treatment and close monitoring is required. Several factors may contribute to the progress to MAS as proposed in a multilayer pathophysiology model [2]. This includes patients' genetics, inflammatory activity of the autoimmune condition and triggers such as infections. Together, this leads to a 
disturbance in immune homeostasis, with abnormal activation of immune cells, especially $\mathrm{T}$ cells, natural killer (NK) cells and macrophages, and an overproduction of inflammatory cytokines, which, when reaching a critical threshold, results in manifest MAS. Particularly viral infection is thought to be a common trigger for development of MAS, such as Epstein Barr Virus (EBV), other Herpes viruses or H1N1 influenza viruses, but also infection with Leishmania [3]. On the other hand, the occurrence of MAS following vaccinations is extremely rare. Some cases of MAS after measles or influenza vaccination have previously been reported in a very small number of patients [4] [5]. Recently, three cases of MAS after SARS-CoV-2 vaccination with ChAdOx1 nCoV-19 (viral vector vaccine, Oxford-AZ) and one case in China with an unknown vaccine agent were reported, though without discussion of immunological mechanisms of MAS development [6] 7. Also, two case reports of de-novo AOSD following COVID-19 vaccination have been published, one after mRNA-1273 (mRNA vaccine, ModernaTX) vaccine and one after ChAdOx1 nCoV-19 [8]. Recent case studies further described inflammatory myocarditis-like illness after vaccination with different vaccines (BNT162b2 (mRNA vaccine, BioNTech/Pfizer) as well as with mRNA-1273 and Ad.26.COV2.S (viral vector vaccine, Johnson \& Johnson)), although pathophysiological hypotheses could not be established [9].

We report the case of a twenty-year-old female with AOSD, who developed a manifest MAS six days after receiving her first vaccine dose of BNT162b2.

\section{Case presentation}

The patient was first diagnosed with AOSD in August 2020 and had experienced one relapse in February 2021 with skin rash, arthralgia, fever, liver failure and hyperferritinemia ( $\max .17,092 \mu \mathrm{g} / \mathrm{l}$; ref.: $13-150 \mu \mathrm{g} / \mathrm{l}$ ). At the time of SARS-CoV-2 vaccination, the patient had been in stable condition for more than three months under maintenance therapy with anakinra $(2 \times 100 \mathrm{mg} / \mathrm{d})$ and prednisolone $(5 \mathrm{mg} / \mathrm{d})$.

Six days after the first vaccination, she reported severe fatigue and intermittent fever episodes $\left(>39.5{ }^{\circ} \mathrm{C}\right)$. In the following days, she experienced severe myalgia, a sore throat, nausea, tremor, sweating and dizziness. Arthralgia or skin rash were absent. Laboratory results showed highly elevated serum ferritin $(136,680 \mu \mathrm{g} / \mathrm{l})$, triglycerides $(352 \mathrm{mg} / \mathrm{dL} ;<200 \mathrm{mg} / \mathrm{dL})$, serum calprotectin / S100A8/9 ( $>24 \mu \mathrm{g} / \mathrm{l} ;<2.94 \mu \mathrm{g} / \mathrm{l})$, sIL-2-R (14'068 UI/ $\mathrm{ml} ;<710.0 \mathrm{UI} / \mathrm{ml})$, LDH $\left(3^{\prime} 136 \mathrm{U} / \mathrm{L} ; 135-250 \mathrm{U} / \mathrm{L}\right)$, CRP (46 mg/L; $<5 \mathrm{mg} / \mathrm{L})$, CD169/SIGLEC1 expression on monocytes (5753 AG/cell; <2400 AG/cell), liver and cholestasis parameters, signs of coagulopathy (elevated d-dimers $(>35 \mathrm{mg} / \mathrm{L} ;<0.5 \mathrm{mg} / \mathrm{L})$, INR (1.35; 0.9-1.25), low fibrinogen $(0.7 \mathrm{~g} / \mathrm{L} ; 1.7-4.2 \mathrm{~g} / \mathrm{L}))$ and a pancytopenia (platelets 103/nl, leukocytes 3.75/nl, hemoglobin $10.4 \mathrm{~g} /$ dL; full laboratory workup in Additional file 1: Table S1). SARS-CoV-2 PCR test, as well as blood and urine cultures, were negative. Abdominal ultrasound and echocardiography showed significant hepatosplenomegaly and a small pericardial effusion. The calculated HScore was 272 points indicating a very high probability $(>99 \%)$ for MAS [10].

Treatment with methylprednisolone $(250 \mathrm{mg} / \mathrm{d}$ intravenously) and intravenous immunoglobulins was started, and anakinra was increased to $3 \times 100 \mathrm{mg} / \mathrm{d}$ subcutaneously. Initial treatment response was moderate with reduced but remaining fever, decreasing ferritin levels, and normalizing cell counts after four days. She eventually received additional ciclosporin to achieve stable remission $(2 \times 100 \mathrm{mg} / \mathrm{d})$. After 2 weeks, she could be discharged with her previous anakinra dose, ciclosporin and a steroid tapering regimen.

Despite her immunosuppressive treatment, the first vaccination had shown positive antibody development against SARS-CoV-2. Her planned second vaccination with BNT162b2 was interdisciplinary discussed, but eventually we recommended to wait for synthetic protein-based vaccine (e.g. NVX-CoV2373 (protein-based vaccine, Novavax)) to be approved by regulators, in the hope for a less inflammatory response.

Follow-up over a period of 4 month showed disease control and no clinical signs of relapse. Maintenance therapy during this period consisted of prednisolon $(5 \mathrm{mg} / \mathrm{d})$, anakinra $(2 \times 100 \mathrm{mg} / \mathrm{d})$ and ciclosporin $(2 \times 100 \mathrm{mg} / \mathrm{d})$. In a further step we plan to taper the ciclosporin to a reduced dose $(2 \times 50 \mathrm{mg} / \mathrm{d})$.

\section{Discussion and conclusions}

The new mRNA vaccines have generally shown a very reassuring safety profile. Nevertheless, it has been shown that nucleic acids in general, including mRNA, may become a target of pattern recognition receptors (PRR) [11]. Also, mRNA vaccines have been shown to act as pathogen-associated molecular patterns that activate toll-like receptors (TLR)-3-7 and -8 [12]. Stimulation of subsequent RNA sensors, such as RIG-I, MDA5 and OAS result in type I interferon (IFN) answer, which leads to maturation of dendritic cells, upregulation of MHC (major histocompatibility complex)-I and MHC-II as well as cytokine and chemokine expression [12-14]. Importantly, under type I IFNs, NK cells enhance IFN- $\gamma$ production, which among many effects further stimulates macrophage activity [14]. In our patient a systemic type I IFN activation could be verified with significantly elevated CD169/SIGLEC1, a surrogate 
biomarker for type I IFN activity established in systemic lupus erythematosus, other rheumatic diseases and viral infections [15] 16. Overall, the new mRNA have been designed to provoke a broad immunological reaction including the innate and adaptive immune system [12]. One assumption might be that while protein-based vaccines tend to stimulate more B cellular pathways, those requiring a mRNA passage before the expression of the protein may stimulate more significantly also other cellular and inflammatory pathways involved in MAS. However, the exact mechanism by which type I IFN triggers MAS in our patient cannot be answered in detail and remains a hypothesis. In a majority of people vaccination leads to the anticipated effective production of antibodies and controlled $\mathrm{T}$ cell response without development of disease flares or induction of other autoimmune responses [17]. In few exceptions, such as in immune systems prone to highly inflammatory responses, also mRNA vaccines might act as trigger in MAS development.

To the best of our knowledge, this is the first case report of development of MAS in a patient with preexisting AOSD after vaccination in general, and SARS-CoV-2 vaccination in particular. Rare vaccine complications, especially in patients with autoimmune or autoinflammatory conditions are important to monitor and register. However, they do not diminish the overall very good safety profile and overwhelming positive benefit-risk ratio of licensed COVID-19 vaccines. Patients with rheumatic and autoimmune diseases are strictly advised to receive a SARS-CoV-2 vaccination, but should be carefully followed-up for signs of autoimmune complications. It remains difficult to establish causality in the case of rare adverse events, especially with preexisting conditions, and more studies are needed to address the incidence of specific autoimmune events following COVID-19 mRNA vaccination.

In a final statement we would like to underline the high safety and efficacy of SARS-CoV-2 vaccines in general to avoid any misinterpretations of this case report. It is crucially important for societies to attain a high vaccination rate for further control of the worldwide COVID-19 pandemic.

\footnotetext{
Abbreviations

AOSD: Adult-onset Still's disease; MAS: Macrophage activation syndrome; PCR: Polymerase chain reaction; sIL-2-R: Soluble interleukine 2 receptor; LDH: Lactate dehydrogenase; IFN: Interferone; CRP: C reactive protein; TLR: Toll-like receptors; RIG-I: Retinoic acid-inducible gene I); MDA5: Melanoma differentiation-associated protein 5; OAS: Oligoadenylate synthetases; MHC: Major histocompatibility complex.
}

\section{Supplementary Information}

The online version contains supplementary material available at https://doi. org/10.1186/s41927-021-00237-9.

Additional file 1. Full laboratory workup.

\section{Acknowledgements}

None.

Authors' contributions

FM and US conceived of the case study and wrote the manuscript. MK, LES, TR and GB corrected the manuscript and contributed to solving the clinical case. All authors read and approved the final manuscript.

Funding

Open Access funding enabled and organized by Projekt DEAL.

\section{Availability of data and materials}

The datasets used and/or analysed during the current study are available from the corresponding author on reasonable request.

\section{Declarations}

\section{Ethics approval and consent to participate}

There is no ethical vote for simple case report needed when a signed patient consent is present at our institution: the patient gave written consent for publication of personal or clinical details.

\section{Consent for publication}

The patient gave written consent for her personal or clinical details to be published in this study.

\section{Competing interests}

The authors declare that they have no competing interests.

\section{Author details}

${ }^{1}$ Department of Nephrology and Medical Intensive Care, Charité - Universitätsmedizin Berlin, Berlin, Germany. ${ }^{2}$ Department of Rheumatology and Immunology, Charité - Universitätsmedizin, Berlin, Germany. ${ }^{3}$ Department of Rheumatology and Systemic Inflammatory Diseases, Universitätsklinikum Hamburg-Eppendorf, Hamburg, Germany. ${ }^{4}$ Department of Infectious Diseases and Respiratory Medicine, Charité - Universitätsmedizin, Berlin, Germany.

Received: 22 September 2021 Accepted: 21 October 2021

Published online: 28 December 2021

\section{References}

1. Efthimiou P, Kadavath S, Mehta B. Life-threatening complications of adultonset Still's disease. Clin Rheumatol. 2014;33:305-14.

2. Strippoli R, Caiello I, De Benedetti F. Reaching the threshold: A multilayer pathogenesis of macrophage activation syndrome. J Rheumatol. 2013:40:761-7.

3. Hashemi-Sadraei N, Vejpongsa P, Baljevic M, Chen L, Idowu M. EpsteinBarr virus-related hemophagocytic lymphohistiocytosis: hematologic emergency in the critical care setting. Case Rep Hematol. 2015;2015:1-6.

4. Otagiri T, Mitsui T, Kawakami T, Katsuura M, Maeda K, Ikegami T, et al. Haemophagocytic lymphohistiocytosis following measles vaccination. Eur J Pediatr. 2002;161:494-6.

5. Ikebe T, Takata H, Sasaki H, Miyazaki Y, Ohtsuka E, Saburi Y, et al. Hemophagocytic lymphohistiocytosis following influenza vaccination in a patient with aplastic anemia undergoing allogeneic bone marrow stem cell transplantation. Int J Hematol. 2017;105:389-91.

6. Attwell L, Zaw T, McCormick J, Marks J, McCarthy H. Haemophagocytic lymphohistiocytosis after ChAdOx1 nCoV-19 vaccination. J Clin Pathol. 2021:25:1-3. 
7. Tang LV, Hu Y. Hemophagocytic lymphohistiocytosis after COVID-19 vaccination. J Hematol Oncol. 2021;14:1-5.

8. Leone F, Cerasuolo PG, Bosello SL, Verardi L, Fiori E, Cocciolillo F, et al. Adult-onset Still's disease following COVID-19 vaccination. Lancet Rheumatol. 2021;9913:21-3. https://doi.org/10.1016/s2665-9913(21)00218-6.

9. Atkins M, Bakhshi H, Chaudhri S. Myocarditis temporally associated with COVID-19 vaccination. Circulation. 2021

10. Fardet L, Galicier L, Lambotte O, Marzac C, Aumont C, Chahwan $D$, et al. Development and validation of the hscore, a score for the diagnosis of reactive hemophagocytic syndrome. Arthritis Rheumatol. 2014;66:2613-20

11. Tatematsu M, Funami K, Seya T, Matsumoto M. Extracellular RNA sensing by pattern recognition receptors. J Innate Immun. 2018;10:398-406.

12. Pardi N, Hogan MJ, Porter FW, Weissman D. mRNA vaccines-a new era in vaccinology. Nat Rev Drug Discov. 2018;17:261-79. https://doi.org/10. 1038/nrd.2017.243

13. Velikova T, Georgiev T. SARS-CoV-2 vaccines and autoimmune diseases amidst the COVID-19 crisis. Rheumatol Int. 2021;41:509-18. https://doi. org/10.1007/s00296-021-04792-9.
14. Wang BX, Fish EN. Global virus outbreaks: Interferons as 1st responders. Semin Immunol. 2019:43:101300.

15. Rose T, Grützkau A, Hirseland H, Huscher D, Dähnrich C, Dzionek A, et al. IFNa and its response proteins, IP-10 and SIGLEC-1, are biomarkers of disease activity in systemic lupus erythematosus. Ann Rheum Dis. 2013;72:1639-45

16. Doehn JM, Tabeling C, Biesen R, Saccomanno J, Madlung E, Pappe E, et al. CD169/SIGLEC1 is expressed on circulating monocytes in COVID-19 and expression levels are associated with disease severity. Infection. 2021. https://doi.org/10.1007/s15010-021-01606-9.

17. Geisen UM, Berner DK, Tran F, Sümbül M, Vullriede L, Ciripoi M, et al. Immunogenicity and safety of anti-SARS-CoV-2 mRNA vaccines in patients with chronic inflammatory conditions and immunosuppressive therapy in a monocentric cohort. Ann Rheum Dis. 2021;Cid:1-6.

\section{Publisher's Note}

Springer Nature remains neutral with regard to jurisdictional claims in published maps and institutional affiliations.
Ready to submit your research? Choose BMC and benefit from:

- fast, convenient online submission

- thorough peer review by experienced researchers in your field

- rapid publication on acceptance

- support for research data, including large and complex data types

- gold Open Access which fosters wider collaboration and increased citations

- maximum visibility for your research: over $100 \mathrm{M}$ website views per year

At BMC, research is always in progress.

Learn more biomedcentral.com/submissions 